\title{
O PAPEL DA LOGÍSTICA NAS ORGANIZAÇÕES: UM ESTUDO DE CASO EM UMA DISTRIBUIDORA DE ALIMENTOS
}

Douglas Fernandes, Josélia Galiciano Pedro, Daryane dos Santos Coutinho, Diego Trevisan de Vasconcelos, Regiane Souza dos Reis Silva, Rosilei de Lima Saraiva

Curso Superior de Tecnologia em Gestão Comercial - Universidade do Oeste Paulista - UNOESTE. E-mail: joselia@unoeste.br

\section{RESUMO}

Em um mercado cada vez mais competitivo, muitas organizações buscam diferenciais, e a aplicação eficaz da logística se torna uma vantagem competitiva, uma vez que realiza planejamentos para armazenar, transportar e controlar um determinado produto. Para acompanhar essas mudanças, as organizações passam por transformações, para se adequarem a tendência de mercado, investe em pesquisa e desenvolvimento da logística, desta forma o cliente tem o produto/serviço o mais rápido e com a qualidade que tanto almeja. Esta pesquisa se justifica por analisar a logística como vantagem competitiva em uma distribuidora de alimentos e por demonstrar o planejamento da reestruturação da logística da mesma. Sendo assim, o objetivo geral deste estudo foi analisar os fatores positivos e negativos na reestruturação da logística em uma distribuidora de alimentos. No que se refere às características metodológicas, utilizou uma abordagem qualitativa, uma pesquisa de caráter descritivo e como instrumentos de coleta de dados pesquisa bibliográfica em livros, artigos científicos e questionário. Após o levantamento das informações bibliográficas foi realizado um estudo de caso com aplicação de questionário ao supervisor da empresa. Desta forma, percebemos que a empresa utilizou à logística como uma ferramenta para atender suas necessidades e principalmente a satisfação dos seus clientes.

Palavras-chave: Logística.Vendas. Reestruturação.

\section{INTRODUÇÃO E OBJETIVO}

A economia tem influenciado muito as organizações a buscarem novas estratégias e se preparar para as mais diversas situações que envolvam os stakeholders ${ }^{1}$ e assim permitindo que estas estejam sempre à frente da concorrência no que se refere à obtenção de vantagem competitiva, e consequentemente obter retorno financeiro acima do esperado pelos sócios.

"Qualquer organização que use ou produza bens, tem que se preocupar com os problemas de movimentá-los de um local para outro, o que obviamente, envolve alguma forma de transporte." (UELZE, 1974, p. 41). Desta forma, que independente do tamanho de uma empresa, uma vez que produza um bem ou serviço ela utilizará da logística do transporte.

A Logística tem como função buscar o melhor caminho com menor custo e maior rapidez, sem esquecer que isso pode ser relativo, pois pode haver ocasiões em que rapidez vai

\footnotetext{
${ }^{1}$ Stakeholders designa uma pessoa, grupo ou entidade com legítimos interesses nas ações e no desempenho de uma organização e cujas decisões e atuações possam afetar, direta ou indiretamente, essa organização.
} 
gerar mais custos, entretanto será agregado mais valor ao produto por chegar ao seu destino em menor tempo.

De acordo com Christopher (2007, p. 3):

Logística é o processo de gerenciamento estratégico da compra, do transporte e da armazenagem de matérias-primas, partes e produtos acabados (além dos fluxos de informação relacionados) por parte da organização e de seus canais de marketing, de tal modo que a lucratividade atual e futura sejam maximizadas mediante a entrega de encomendas com o menor custo associado.

Desta forma, a logística é utilizada com uma das vantagens competitivas da organização, pois trata de um planejamento necessário para o transporte seguro e controlado na entrega de um determinado produto.

De acordo com Christopher (2007) o serviço oferecido ao cliente pode proporcionar a diferença entre sua empresa e a de seus concorrentes, ou seja, o nível de satisfação dele sobre seus serviços e produtos é usado como vantagem competitiva sobre os produtos concorrentes.

A logística faz com que todo o planejamento desenvolvido pela empresa seja alcançado de maneira eficaz até que chegue ao consumidor final. É cada vez mais comum às organizações utilizarem esta ferramenta, como forma segura e bem planejada de fornecer seus produtos e serviços para seus destinatários, com isto, melhorando o acesso dos fornecedores com os clientes, de maneira que ele venha receber seu produto/serviço com maior comodidade em menor tempo, com a mesma qualidade, atendendo as expectativas destes, ou melhor, superandoas para que venham sentir-se satisfeitos em relação aos prazos e condições em que o mesmo foi solicitado.

Apesar, da logística ser responsável pelas grandes alavancadas do sucesso de muitas organizações, é cada vez mais comum estas empresas passarem por imensos problemas, já que reduzir custos com estocagens e o tempo de entrega nem sempre é tarefa fácil, cabe aos gestores desenvolverem estratégias para diminuir esses problemas.

Desta forma, essa pesquisa tem por objetivo, demonstrar como uma reestruturação na logística, quando realizada de maneira eficaz pode afetar positivamente uma empresa no ramo alimentício. Será discutido como a reestruturação pode ajudar a empresa incrementar da melhor forma suas atividades e cumprir seus objetivos com seus clientes, levando em conta às obrigações 
e necessidades de ambas as partes, tornando possíveis metas em alvos viáveis para o sucesso no mercado competitivo.

\section{METODOLOGIA}

Segundo Oliveira com a pesquisa qualitativa (2007, p. 117): "busca-se descrever a complexidade de uma hipótese ou problema, analisar a interação de certas variáveis, compreender e classificar processos dinâmicos experimentados por grupos sociais, apresentar contribuições no processo de mudança, criação ou formação de opiniões de determinado grupo permitir, em maior grau de profundidade, a interpretação das particularidades dos comprometimentos ou atitudes dos indivíduos".

Desta forma, essa pesquisa torna-se qualitativa, pois tem seu foco uma análise na reestruturação da logística de uma empresa de distribuição de alimentos, procurando concentrarse na questão das pessoas, ou seja, de que modo uma mudança desse gênero pode afetar positivamente ou negativamente a vida profissional e social dos funcionários presentes na organização.

Cervo e Bervian (2011), a pesquisa descritiva observa, registram, analisa e correlaciona fatos ou fenômenos (variáveis) sem manipulá-los. Desse modo, esse método de pesquisa envolve uma atenção especial, pois este estará observando fatos que podem ocorrer tanto em um comportamento individual quanto em uma corporação, seja ela; político econômico ou sociocultural, e que logo mais irá discorrer sobre os assuntos e fatos ali examinado de forma verídica.

“Estudo de caso é a pesquisa sobre um determinado indivíduo, família, grupo ou comunidade que seja representativo do seu universo, para examinar aspectos variados de sua vida" (CERVO e BERVIAN, 2009, p. 67). Assim, o estudo de caso procura averiguar acontecimentos no decorrer do tempo de vida de alguma coisa, seja ela em alguém ou em uma organização. Desse modo, a pesquisa realizará o estudo de caso em uma distribuidora de alimentos.

Os instrumentos de coleta de dados que foram utilizados no estudo foram: pesquisa bibliográfica e questionário. A pesquisa bibliográfica procura explicar um problema a partir de referências teóricas publicadas em artigos, livros, dissertações e teses. (CERVO e BERVIAN, 2011). Ou seja, pode-se usar desta ferramenta para responder, questionar, avaliar entre outros, sobre os mais variados temas e títulos. Desta forma será utilizado método para fundamentar e responder os assuntos aqui proposto. 
Questionário é a forma mais usada para coletar dados, pois possibilita medir com mais exatidão o que se deseja. (CERVO e BERVIAN, 2011). Neste sentido, faz se necessário utilizar o questionário para adquirir dados mais precisos e confiáveis de forma mais específica, possibilitando assim maior clareza e entendimento dentro de uma organização.

\section{RESULTADO}

O universo da pesquisa realizada contemplou o supervisor da empresa pesquisada, no qual definiu o que seria uma roterização, ou seja, trata-se de um roteiro ou um plano de viagem criado para customizar os custos de uma determinada viagem ou caminho. Deste modo, entende-se por roterização todo o planejamento logístico, ou seja, planejar o melhor percurso ao menor custo possível em menor tempo. O supervisor afirmou que a organização cada vez mais deve investir e buscar soluções para reduzir o percurso e tempo de viagem, desta forma vai economizar combustível, tempo do motorista ou vendedor.

No que se refere à reestruturação foi necessário para que a organização se mantivesse competitiva no mercado de trabalho, pois segundo o supervisor cada ano que passa o mercado se torna mais competitivo se não houver a reestruturação e investimentos, este fora do mercado. Assim, depois que houve a reestruturação foi implantado um sistema informatizado que calcula os custos do roteiro e indica o melhor caminho a percorrer, considerando a menor quilometragem, evitando desta forma as idas e vindas em um mesmo percurso.

Relatou também que quando se fala em mudança, é inevitável não ter demissões e/ou contratações, com essa empresa não foi diferente. Todo o processo de reestruturação existe demissão e contratação, pois é uma forma de se adequar as novas mudanças e hoje deve existir esta flexibilidade nas pessoas e a quebra dos próprios paradigmas que são criados dentro das organizações. Assim, os funcionários tantos os novos quanto os antigos que ficaram na empresa, tiveram que passar por treinamentos para poder estar prontos e qualificados para o novo período que se sucedeu. Deve existir uma adequação por parte da organização no sentido de instruir e preparar o colaborador na busca do objetivo que atenda as necessidades da empresa como seus próprios objetivos e de seus colaboradores sempre visando o bem estar de todos. 


\section{DISCUSSÃO}

Ao analisarmos as informações obtidas, verificamos que a empresa deve investir sempre, em pessoas qualificadas e treinadas, e buscar novas tecnologias para planejar suas rotas desde a busca pela matéria prima, passando pelo setor de vendas até chegar aos compradores, seja eles de grande porte ou não, pois se a empresa possuir um bom planejamento, consequentemente economizará tempo e dinheiro.

Quando uma corporação passa por uma reestruturação no seu ambiente interno ou externo, é para acarretar mudanças, seja ela no espaço físico, no quadro de funcionários, ou até mesmo na segmentação de mercado. Independente do ramo em que a empresa atua, ela sempre deverá estar desenvolvendo estratégias competitivas para estar à frente de seus concorrentes, por uma questão de sobrevivência no mercado. Desta forma, evitando gastos desnecessários e reduzindo custos, a empresa certamente alcançará seus objetivos.

Para que a empresa fosse adaptada a essa reestruturação, fez necessária a troca de funcionários, uns saíram e novos entraram até mesmo por uma questão de acomodação, ou seja, novas estratégias, nova direção. A empresa quer que seu funcionário sinta-se motivado e para isso investe no seu potencial, entretanto cabe ao próprio colaborador buscar capacitação, se atualizar no mercado e principalmente especializar-se, além de ser um diferencial no meio de tanta gente buscando empregos e até mesmo sua vaga, no mercado de trabalho.

Sendo assim, destacamos que, mesmo com objetivos e metas cumprida para essa fase, a empresa não relaxa, procurando constantemente novas estratégias para estarem reduzindo custos, obtendo melhor resultado financeiro e alcançando a excelência no padrão de qualidade de seus produtos e funcionários.

\section{CONCLUSÃO}

Na pesquisa realizada, podemos verificar que ao elaborar e aplicar o planejamento logístico, o fluxo ocorre naturalmente, ou seja, há o tempo certo da chegada da matéria prima, a transformação em produtos e a saída para os pontos de carga e descarga até chegar ao destinatário. Entretanto não é possível se obter o ritmo ideal, para a empresa ser à prova de falhas, já que não há como prever o que acontece no percurso entre a fábrica e o cliente final.

Observamos também que a logística é imprescindível, quando se trata de obter um diferencial sobre seus concorrentes, já que atualmente o comércio eletrônico vem ganhando 
força, e neste contexto a logística se faz mais presente do que nunca, fazendo essa conexão entre a fábrica, lojas e o consumidor.

Atualmente uma empresa que não utiliza a logística como uma das ferramentas para melhorar seus negócios, tem uma grande chance de ser 'engolida' por outras empresas bem sucedidas não importando o ramo em que atua. Os consumidores estão cada vez mais exigentes, e as empresas precisam se adequar a esta nova realidade, estabelecer uma logística eficiente, que possibilitem que a logística estabelecida pela empresa realmente funcione possibilitando deste modo o crescimento da mesma, bem como uma reputação que a consolide no mercado competitivo atual.

Desta forma, podemos concluir que a distribuidora de alimentos, optou em realizar uma reestruturação a fim de se atualizar no mercado, e corrigir alguns erros que estavam afetando a vida financeira da empresa. No qual destacamos a comunicação na falta de estoque, altos custos do frete e percursos longos.

Entretanto a pesquisa revelou que a empresa possui uma vasta experiência, já que está a mais de trinta e oito anos no mercado e provou que sabe à hora exata em se reinventar para não ficar para trás no mercado altamente competitivo.

\section{REFERÊNCIAS}

CERVO, A. L; BERVIAN, P. A. SILVA, R. Metodologia científica. 6a ed. São Paulo: Pearson. 2009

CHRISTOPHER, M. Logística e gerenciamento da cadeia de suprimentos. 2a ed. São Paulo: Cengage Learning. 2009

OLIVEIRA, S. L.. Tratado de metodologia científica: projetos de pesquisas, TGI, TCC, monografias, dissertações e teses: Pioneira, 2007.

UELZE, R. Logística empresarial: uma introdução à administração dos transportes. São Paulo: Pioneira, 1974. 